\title{
Encoded Archival Description (EAD): Adoption and Implementation
}

\author{
Jihyun Kim* and Elizabeth Yakel \\ University of Michigan School of Information, 550 East University, Ann Arbor, Ml 48109-1092. \\ Email: \{jhkz, yakel\}@umich.edu,
}

\begin{abstract}
Encoded Archival Description (EAD) provides archival researchers with more in-depth contentrelated and contextual information than was previously available anywhere but in the physical repository. This has led to its use throughout the United States and in many other countries to increase access to archival and manuscript collections. Furthermore, EAD is one means of managing metadata that describe digital objects linked to archival finding aids. In spite of these potential benefits, the archival community in the United States has embraced EAD slowly. This paper examined EAD adoption in the U.S. and reports on a survey of 399 archives and manuscript repositories that participated in EAD educational workshops from 1993 - 2002. Among the factors found to be related to EAD adoption were prior adoption of the MARC format for the description of archival or manuscript materials and professional staff size. Implementation issues affecting adoption included the different technologies and skills required for encoding and display of finding aids and the lack of a consensus on either encoding software or display options.
\end{abstract}

\section{Introduction}

The growth of the Internet increased the ability of archives and special collections to provide ever more detailed information online. However, the ability to publish descriptions of primary sources did not decrease the need for a new descriptive standard which would allow for consistent display of and facilitate the exchange and searching of archival information across different repositories. In response to this situation, the archival descriptive standard, Encoded Archival Description (EAD), was developed in the early 1990's. EAD is based on SGML/XML structures yet incorporates and builds on current descriptive practices, such as MARC and the structure of paper finding aids (Kiesling 1997). Therefore, EAD represents an evolution of archival description firmly rooted in previous practices in the archival community.

Several case studies concerning EAD adoption and implementation have been published since it was developed.
Although these studies suggest that EAD has been widely adopted in the archival community, there is little empirical evidence concerning which factors help or hinder EAD adoption. The present study addresses this issue and is based on a quantitative analysis from a survey of 399 archival institutions.

Our analysis is based on the theory of diffusion of innovation proposed by Everett M. Rogers (1995). Rogers' theory is extensive. One aspect of his theory concerns the characteristics which influence the rate of adoption. These are: relative advantage, compatibility, complexity, trialability, observability. In this paper, we concentrate on two -- compatibility and complexity. According to Rogers, compatibility is the extent to which an innovation is consistent with existing values, practices, or needs of the potential adopters. He suggests that when an innovation is compatible, potential adopters will be more likely to accept it. Rogers defines complexity as the degree to which an innovation is easy or difficult to understand and use. $\mathrm{He}$ asserts that if an innovation is complex to learn and use, potential adopters will be reluctant to embrace it. Compatibility and complexity were selected because Rogers noted that in previous studies these two concepts have consistently explained why some innovations were accepted and while others were rejected. Since EAD is a new practice in the archival community, we considered it an innovation. Thus, the present study adapted Rogers' theory and examines how compatibility and complexity affected the adoption of EAD in the archives surveyed.

\section{Literature Review}

Rogers (1995), a communication theorist and researcher, proposed a comprehensive theoretical framework concerning how innovations spread through social systems over time, and what characteristics of the innovation affected adoption. By adoption, Rogers meant "a decision to make full use of an innovation as the best course of action available (p.37)." In his book, he demonstrates how his theory can be applied to innovation in various fields, such as public health, management, communication and sociology.

Although this study is the most extensive, ours is not the first to apply Rogers' theory to EAD adoption. Two other studies of EAD based on the diffusion of innovation theory exist. Tatem (1998) applied the five characteristics of an innovation to analyze barriers of EAD implementation. She

*Corresponding author 
explored the relative advantage of EAD, its compatibility with existing archival practices and beliefs, complexity, trialability and observability. She focused on the obstacles perceived by archivists as stated in electronic discussion lists, conference papers and comments. She identified the negative perceptions of EAD based on these five characteristics. Tatem concluded that wide-scale adoption of EAD would not take place unless the proponents of EAD were able to change the negative perceptions of EAD's complexity and usefulness. Moreover, she argued that usercentered research on EAD would be the best means for demonstrating advantages of this standard.

Marshall (2002) conducted the other study of EAD based on the diffusion of innovation theory. Her survey of early EAD implementers focused on the process of transition from innovation to institutionalization, which Rogers identified as a sub-process of the innovation-decision process in organizations. This sub-process is at the end of the innovation-decision process, when the innovation has finally lost its distinctive quality and its separate identity as a new idea has disappeared. In this respect, Marshall's study differs from our because we focus on adoption, a middle stage of the innovation-decision process.

The results of Marshall's (2001) survey indicated that a majority of early implementers perceived EAD as an institutional need since it enabled the creation of better access tools. Marshall noted, however, that few institutions did anything in the way of user studies and they only had an elementary grasp of the true costs of EAD implementation. Thus, the findings of the study also emphasized these two important aspects for future research.

Two other institutional surveys concerning EAD implementation exist. Minks and Curtis (2002) conducted a large-scale survey targeting AMIGOS member libraries. The purpose of the survey was to develop a best practice document for EAD implementation in small academic libraries in the AMIGOS region. Their analysis of 100 surveys found that the typical $\mathrm{EAD}$ implementation occurred at an institution of over 20,000 students, indicating that institutional size was a factor in implementation. Their analysis also showed that although a majority of responding institutions was already involved in consortial projects, they were interested in seeking more partnering opportunities for implementing EAD.

While Minks and Curtis (2002) conducted the survey to gather information about overall implementation of EAD, Roth (2001) focused on the current deployment or delivery methods for EAD finding aids in order to identify best practices. He defined the phrase 'deployment method' as "any electronic delivery system bringing EAD-encoded finding aids to end-users via the Internet." $\mathrm{He}$ also examined how archivists perceived the utilization of EAD finding aids and evaluated the basis of their perceptions.
Roth's findings, based on data from thirty-one institutions, concerned deployment methods. He indicated that archivists selected these because of relative ease of use, accessibility, availability and affordability. The problems identified by respondents included not enough time or staff to create and manage the finding aids and difficulty in learning the networking and programming skills essential for setting up the software applications and middleware to deliver EAD finding aids. Roth also found that a single ideal deployment method had not yet been developed. In addition, since many of the deployment methods were no longer supported, or had suspended sales, respondents believed it necessary to set forth more sophisticated technologies for improving implementation of EAD finding aids.

Other studies exist that have analyzed adoption of related innovations in the archival community. In addition to studies concerning EAD adoption, Duff (1997) conducted a large-scale survey concerning the use of Rules for Archival Description (RAD) in Canada. RAD is a data content standard for describing archival collections that was developed in the late 1980's. Duff's survey data were collected from 258 Canadian Council of Archives (CCA) member institutions. Her results showed that $71 \%$ of the responding institutions had adopted $\mathrm{RAD}$. Furthermore, the adoption of RAD had a definite impact on Canadian descriptive practices in terms of the level of description. While item level description had been popular in Canadian archives prior to the adoption of RAD, Duff's results indicated that more archives had begun to describe archival materials on the series and file rather than the item level after implementing RAD. By allowing for multi-level description, Duff argued that RAD influenced this critical change in the level of description.

Most relevant to the present study, are the studies of MARC adoption in the archival community. MAchine Readable Cataloging (MARC) began as a library-oriented descriptive standard that enabled searching across large union databases of the bibliographic holdings in different libraries in the United States and throughout the world. As the library community was developing the MARC standard, the archival community still relied on printed union catalogs, such as National Union Catalog of Manuscript Collections (NUCMC), to provide union access to manuscript collections in different archival institutions. By observing the success of MARC adoption in the library community, however, archivists realized that union access to archival collections was more achievable through the incorporation of descriptive standards and the use of networked computer databases, rather than print technology. Responding to these trends, archivists developed the US MARC format for Archival and Manuscripts Control (AMC) (Ruth 2001). 
Since the initiation of the MARC format for archival and manuscript materials, there have been two empirical studies of its adoption. Stout and Baird's (1984) early examination of MARC adoption by colleges and universities and Martin's (1994) later survey demonstrated that the archival community was ambivalent about the adoption of descriptive standards. Both articles also identified a greater interest in standardization and the use of the MARC standard among colleges and universities. Martin surveyed 200 academic archives on the adoption and implementation of MARC. She found that 80 out of 140 respondents adopted MARC. Of those, 59 reported utilization of a bibliographic utility, such as OCLC or RLIN. Therefore, the majority of the MARC adopters were providing union access to their archival collections through the large online databases. This pattern is significant because EAD builds on MARC. The two standards share a cluster of descriptive standards, such as controlled vocabulary, and structure descriptive information in a similar ways.

Literature relevant to the present study indicated that there is little empirical research concerning EAD implementation. Furthermore, other than the Minks and Curtis (2002), the sample sizes of the other studies were very low. Since both Marshall (2002) and Roth (2001) drew their samples from official EAD websites at the Society of American Archivists and the Library of Congress, respectively, the population was also largely early implementers and opinion leaders and did not examine a broad cross section of the archival community. While the studies of RAD and MARC provided some background and an understanding of previous diffusion patterns, we still thought that a large-scale empirical study of a broader population was needed to investigate EAD adoption and the factors that relate to this process.

\section{Methodology}

We employed survey methodology. The questionnaire consisted of 61 closed questions and 3 open-ended questions. In order to draw a more balanced sample from the archival community, the population for our survey was participants in EAD workshops sponsored by the Research Libraries Group and the Society of American Archivists from 1993 to 2002. During this period, 600 individuals attended these workshops. Out of 600 individuals, one participant per archives was selected for receipt of the survey. Thus, in institutions with several archival and / or special collections units, an individual in each unit was surveyed. The unit of analysis for our survey was the archival or manuscript repository. This sampling process resulted in questionnaires being sent to 399 archival or manuscript agencies. Out of the 399 questionnaires sent out, 135 were returned and therefore, the response rate was $34 \%$.
The major research question guiding this project was: How do the factors of compatibility and complexity, affect the adoption of EAD? Since we focused on the factors of compatibility and complexity, we had a series of subquestions concerning each of these factors and the survey was constructed to operationalize these factors.

By compatibility, Rogers (1995) meant the degree to which an innovation was consistent with existing structures, beliefs, practices, or needs of potential adopters. We measured compatibility in terms of several dimensions: existing descriptive practices, staff and collection size, and technological infrastructure. First, compatibility with existing descriptive practices was operationalized as prior adoption of MARC. As an existing descriptive practice in the archival community, MARC employed a common set of standards with EAD. MARC would have given archivists and curators an understanding of data structure standards (e.g., MARC), data content standards (e.g., the AngloAmerican Cataloging Rules or AACR) and data value standards (e.g., the Library of Congress Subject Headings). We therefore assumed that prior adoption of the MARC and its attendant descriptive practices made EAD adoption easier because MARC adopters would already be familiar with the descriptive practices shared by these two standards. Second, previous surveys (Minks and Curtis 2002) had found that staff and collection size were factors in EAD implementation. We wanted to test this. Additionally, our assumption was that because of its complexity, EAD adoption required a certain number of staff members who could dedicate large amounts of time to work with EAD in order to develop and maintain expertise. Therefore, the size of an institution affected its ability to adopt EAD. Third, technological infrastructure was operationalized using two dimensions: 1) whether or not the institutions had technical support staff; 2) whether or not the institutions controlled their own servers. EAD delivery necessitates technical expertise and implementation requires ownership or the ability to influence content and programming on a server. Therefore, technological infrastructure was assumed to be a key element in EAD adoption.

Rogers defined complexity as the degree to which an innovation was easy or difficult to understand and use. Complexity was assessed in terms of the technical aspects necessary for encoding and publication of finding aids. EAD is comprised of two related yet separate operations: encoding and delivery. These require different technological skill sets. Encoding involves knowledge of SGML/XML markup. Publication can necessitate knowledge of server administration, XSL stylesheets, middleware, search engines, and programming or scripting. Therefore, we measured the archives ability to accomplish these two components of EAD. There were three measures representing complexity: 1) types and the number of 
encoding software applications utilized; 2) participation in consortia to publish finding aids; 3 ) the number of encoded finding aids and that of published finding aids. Curators and archivists face many choices in the selection of encoding software, both in terms of the type of application and then the actual brand of software. Each category presents different functionalities, challenges and benefits in the encoding process. Consortia are one means of sidestepping internal difficulties with the delivery of finding aids. Consortia can diminish the amount of complexity by alleviating repositories of the need to maintain expertise in programming middleware or setting up search engines to facilitate the delivery of finding aids. Finally, complexity was measured by comparing the output of these two processes.

\section{Findings}

\section{Demographic Information}

Respondents were analyzed using three types of demographic information: 1) types of archives; 2) professional staff size; 3 ) the total number of collections. This contextual analysis forms a background as to the generalizability of later findings. Figure 1 shows the types of archives and the percentages of both those surveyed and those who responded.

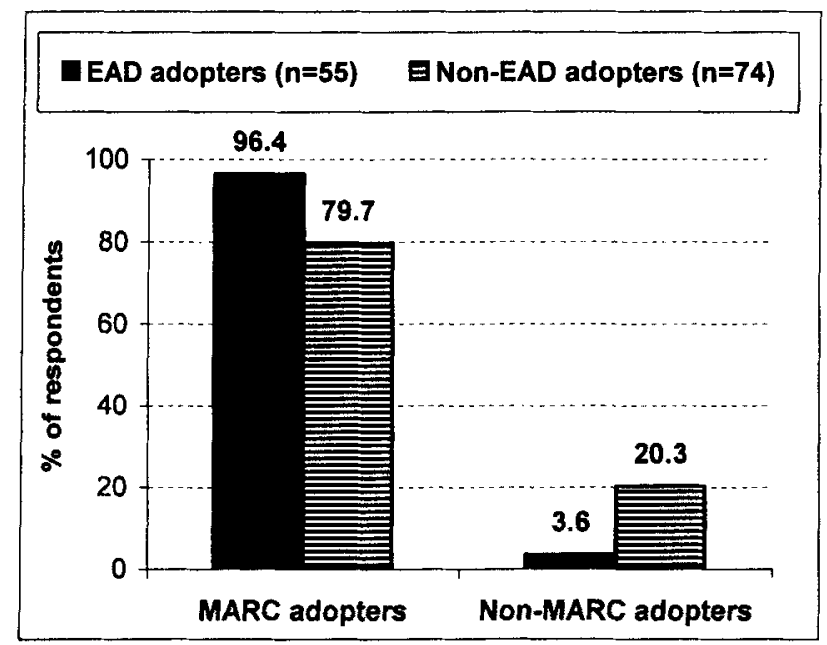

Figure 1. MARC and EAD Adoption

Table 1 demonstrates that the types of surveyed and responding archives showed similar distributions and the types of responding institutions were representative of the survey sample. In both groups of institutions, colleges and universities consisted of $52 \%$. The second most frequent type of institutions represented was governmental bodies. The third most frequent type, in both groups, was museums. Other institutions, such as independent libraries or religious archives, showed slightly different but comparable percentages in both groups.
Table 1. Types of Archives: Surveyed and Responding

\begin{tabular}{|c|c|c|}
\hline Type of Archives & $\begin{array}{c}\text { Surveyed } \\
\text { Archives } \\
(\mathbf{N}=\mathbf{3 9 9})\end{array}$ & $\begin{array}{c}\text { Responding } \\
\text { Archives } \\
(\mathbf{N}=\mathbf{1 3 5})\end{array}$ \\
\hline College or University & $52 \%$ & $52 \%$ \\
\hline Governmental & $12 \%$ & $13 \%$ \\
\hline Museum & $9 \%$ & $11 \%$ \\
\hline Independent Library & $8 \%$ & $7 \%$ \\
\hline Non-Profit organization & $6 \%$ & $3 \%$ \\
\hline Public Library & $4 \%$ & $6 \%$ \\
\hline For-Profit Business & $4 \%$ & $4 \%$ \\
\hline Religious Organization & $3 \%$ & $4 \%$ \\
\hline
\end{tabular}

The professional staff size was measured in terms of Full Time Equivalents (FTE). The overall mean professional staff size was 4.68 FTEs and the median staff size was 3 . This average number was similar to the average, 4.98 FTEs reported in the study by Minks and Curtis (2002). The range was from 0.25 to 38 FTEs. The standard deviation was 6.28 FTEs.

The mean number of collections was 1606.5 and the median was 563 . The number of collections ranged from 1 to 11270 . The standard deviation was 2476.71 . The large range and standard deviation indicated the great diversity in number of collections as a proxy for repository size. In this respect, the professional staff size was a more consistent measurement for size of the archives than the total number of collections.

One of the important findings was how many responding repositories adopted EAD. Out of 135 respondents, 57 (42\%) adopted EAD, whereas $78(58 \%)$ did not. The majority of the respondents, therefore, have not adopted EAD. This result indicated that EAD adoption in the archival community is problematic.

Given that the number of repositories adopting EAD is not as large as might be assumed; the next section of this paper examines potential reasons for these numbers. In order to do this, we address the research question, regarding how the factors of compatibility and complexity influenced the adoption of EAD.

\section{Compatibility}

As noted in the methodology, compatibility was analyzed based on the relationship between EAD adoption and three factors: 1) MARC adoption; 2) institutional size; and 3) technological infrastructure. Three hypotheses were proposed: 
- $\mathrm{H}_{1}$ : Archives that have previously adopted MARC are more likely to adopt EAD.

- $\mathrm{H}_{2}$ : Archives with a larger staff are more likely to adopt EAD.

- $\mathrm{H}_{3}$ : Archives with a stronger technological infrastructure are more likely to adopt EAD.

\section{MARC Adoption}

Our findings indicated that there was a significant relationship between MARC and EAD adoption $(\chi=$ $7.630, \mathrm{df}=1, \mathrm{p}=0.006$ ). In addition, Figure 1 shows the distribution of MARC adopters and non-MARC adopters in two groups; namely, EAD adopters and non-EAD adopters. As seen in the graph, a greater percentage of EAD adopters (96.4\%) than that of non-EAD adopters $(79.7 \%)$ also adopted MARC.

\section{Size of Institutions}

According to Rogers (1995), other studies have consistently found that the size of an institution was positively related to its innovativeness, which showed the extent to which an institution would be relatively earlier in adopting an innovation as opposed to other institutions. Rogers proposed this as one of his generalizations. White (2001) examined factors that affected the adoption and implementation of Digital Reference Services (DRS), within the framework of Rogers' theory. As one of the factors, she measured the size of academic libraries, with financial and staff resources, and examined the relationship between the size and DRS adoption. Her findings confirmed Rogers' generalization by indicating that largersized libraries adopted DRS more quickly. The present study utilized two measures of size: professional staff (FTE) and the total number of collections.

\section{Professional Staff Size}

Professional staff size was also found to be related to The EAD adoption $(\chi=9.096, \mathrm{df}=3, \mathrm{p}=0.028)$. The median professional staff size for EAD adopters was 4; double that of non-EAD adopters (2). Furthermore, the median number of total staff for EAD adopters was 10, over twice the median total staff size (4) for non-adopters.

We had assumed that consortia were a mechanism for lowering the staff size barrier for EAD adoption. This was not so. There was no difference in median staff size for EAD adopters who were consortial participants and those who did not participate in consortia. The median professional staff size for consortial participants was also 4 FTE.

\section{Total Number of Collections}

Total number of collections was also related to EAD adoption $(\chi=9.899, \mathrm{df}=3, \mathrm{p}=0.019)$. While this was not surprising, due to the large standard deviation, this is not a very precise measure. Furthermore, there are no standard metrics for counting archival collections, so we do not view this result as a good measure.

\section{Technological Infrastructure}

$\mathrm{EAD}$ adoption and implementation require technical expertise and equipment, such as hardware, software and network access. The technological infrastructure, therefore, made it possible to keep an EAD initiative viable. Several EAD case studies suggested the importance of having a technological infrastructure. Morris (1997) described EAD implementation of the Harvard/Radcliffe Digital Finding Aids Project. She mentioned that it was essential to have a good relationship with Harvard University's library systems office. The reason for this was that the office provided programming expertise for the design and implementation of search engines, which most archivists were not expected to do by themselves. In addition, Fox (1997) mentioned that servers, at varying archives, played an important role in providing search functions for EAD finding aids.

We measured technological infrastructure in two ways: 1) the existence of a technical support person on staff; and 2) server control. We hypothesized that institutions with stronger technological infrastructures would be more likely to adopt EAD. Chi-Square tests were performed to test for a relationship between either technical support or server control and EAD adoption but no relationship was found. Hypothesis 3, which stated that archives with a stronger technological infrastructure are more likely to adopt EAD, was rejected.

With respect to technical support, $35(62.5 \%)$ out of 52 EAD adopters had technical support, whereas 43 (56.6\%) out of 76 non-EAD adopters received technical support from their parent institutions. Thus, it was found that almost $61 \%$ of the total responded institutions had technical support. In terms of server control, however, $15(27.3 \%)$ out of $55 \mathrm{EAD}$ adopters had their own servers, whereas 18 (24\%) out of 75 non-EAD adopters had their server control. Therefore, only $33(25.4 \%)$ responding institutions had their own servers.

Although the Chi square tests identified a relationship between MARC adoption and professional staff size with EAD adoption, these tests did not demonstrate a direction for that relationship. We therefore turned to a stronger statistical test, logistic regression to see if either of these variables could be considered predictors of EAD adoption. Since the dependent variable, EAD adoption, was binary, logistic regression was selected for the analysis. A regression model was built to estimate whether MARC adoption and / or staff size were positive predictors of EAD adoption. These became predictor variables to explain EAD adoption. The regression model was represented as follows: $y=\beta_{0}+\beta_{1} x_{1}+\beta_{2} x_{2}$ ( $y=$ EAD adoption; $x_{1}=$ MARC adoption; $x_{2}=$ professional staff size). 
Table 2 shows the results of the logistic regression. These indicated that both MARC adoption and professional staff size were statistically significant factors predicting EAD adoption. Based on Exp (B), the odds ratio estimates, MARC adoption increased the likelihood of EAD adoption by 5.998 times, when controlling for another factor, professional staff size. The results also indicated that for every one Full Time Equivalent increase in professional staff size, the likelihood of EAD adoption increased by 1.095 times, after controlling for MARC adoption. Consequently, the logistic regression analysis demonstrated that both MARC adoption and professional staff size were positive predictors of EAD adoption. Due to the fact that MARC adoption is a dichotomous variable and staff size is continuous, the strength of these predictors relative to each other cannot be assessed. Therefore, both Hypothesis 1 and 2 were accepted: 1) Archives that have previously adopted; 2) Archives with a larger staff size are more likely to adopt EAD.

Table 2. Logistic regression analysis

\begin{tabular}{|c|c|c|c|}
\hline & $\mathbf{B}^{1}$ & P-value & $\begin{array}{c}\text { Exp } \\
(\mathbf{B})^{2}\end{array}$ \\
\hline MARC & 1.791 & $0.023^{*}$ & 5.998 \\
Professional Staff & 0.091 & $0.040^{*}$ & 1.095 \\
Constant & -2.317 & 0.788 & 0.099 \\
\hline
\end{tabular}

1. B indicates likelihood estimates.

$P<.05$

2. Exp (B) indicates odds ratio estimates.

\section{Complexity}

Tatem (1998) mentioned that even though EAD proponents made efforts to mitigate the complexity of EAD by providing guidelines and training programs, EAD adopters still uttered frustrations about a steep learning curve and the technical complexity of EAD implementation. Out of 53 EAD adopters, 37 (69.8\%) reported that they experienced difficulties when implementing EAD. This represents a clear majority of EAD adopters. Since the complexity primarily involved technical issues relating to encoding and publication of EAD finding aids, the analysis of complexity focused on three technical aspects: 1) the use of encoding software applications; 2) comparison between the number of institutions that published EAD finding aids themselves versus those that utilized consortia to deliver the finding aids for them; and 3) comparison between the number of encoded finding aids and published finding aids.

\section{Encoding Software Applications}

Fox (1997) mentioned that multiple approaches were available to create EAD-encoded finding aids and thus the complexity was increased. Software options included: SGML editors, text editors, word processors, automated encoding, and databases. Table 3 shows the survey responses to a question on the software applications utilized for encoding EAD finding aids. As seen in Table 3, XML editors were the most frequently used software applications. Although XML editors are the most recently developed software tools for EAD encoding, these have quickly gained popularity.

Table 3. Types of Encoding Software Applications

\begin{tabular}{|c|c|c|}
\hline $\begin{array}{c}\text { Types of } \\
\text { Encoding } \\
\text { Software } \\
\text { Applications }\end{array}$ & $\begin{array}{c}\text { Number of } \\
\text { Archives / Special } \\
\text { Collections } \\
(\mathbf{N}=\mathbf{5 3})\end{array}$ & $\begin{array}{c}\text { Percentage of } \\
\text { Archives / } \\
\text { Special } \\
\text { Collections } \\
(\mathbf{N}=\mathbf{5 3})\end{array}$ \\
\hline XML Editors & 33 & $62.3 \%$ \\
Text Editors & 20 & $37.7 \%$ \\
Word Processors & 18 & $33.9 \%$ \\
SGML Editors & 10 & $18.9 \%$ \\
Databases & 9 & $16.9 \%$ \\
Web-based & & $11.3 \%$ \\
Template & 6 & $9.4 \%$ \\
Automated & & \\
Encoding & 5 & \\
\hline
\end{tabular}

In addition, all of the software applications suggested by Fox were more or less used for EAD encoding. Due to the introduction of XML editors, SGML editors were even less commonly used than text editors or word processors. Consortia usually provided a web-based template for their participants and $11.3 \%$ of EAD adopting institutions employed such a template. Furthermore, Table 4 illustrates that only $25(47.2 \%)$ out of 53 EAD adopters used a single type of software for encoding. A majority of the EAD adopters were simultaneously employing several types of software making the encoding process more complex.

Table 4. Number of Encoding Software Applications Used for EAD Encoding

\begin{tabular}{|c|c|c|}
\hline $\begin{array}{c}\text { Total Number } \\
\text { of Encoding } \\
\text { Software } \\
\text { Applications }\end{array}$ & $\begin{array}{c}\text { Number of } \\
\text { Archives / Special } \\
\text { Collections } \\
(\mathbf{N}=\mathbf{5 3})\end{array}$ & $\begin{array}{c}\text { Percentage of } \\
\text { Archives / Special } \\
\text { Collections } \\
(\mathbf{N}=\mathbf{5 3})\end{array}$ \\
\hline 1 & 25 & $47.2 \%$ \\
2 & 15 & $28.3 \%$ \\
3 & 8 & $15.1 \%$ \\
4 & 4 & $7.5 \%$ \\
6 & 1 & $1.9 \%$ \\
\hline Total & 53 & $100 \%$ \\
\hline
\end{tabular}




\section{Self vs. Consortial Publication}

For publishing EAD-encoded finding aids, EAD adopters could employ two methods: self publication or outsourcing the publication to a consortium. Self publication meant that EAD adopters delivered encoded finding aids on their own web sites. Consortial publication signified that encoded finding aids were sent to the consortia for mounting on the web and therefore the finding aids were published on the consortia's web site. Self publication required maintaining technical expertise within the institution, and therefore, would be more difficult for EAD adopters than using a consortia.

Table 5 shows that $16(31.4 \%)$ out of 51 EAD adopters used self publication and the same number of adopters used consortial publication. Six (11.7\%) archives employed both institutional and consortial publication. An interesting finding, however, was that $13(25.5 \%)$ EAD adopters reported that they had not yet published any encoded finding aids. Thus, almost $57 \%$ of EAD adopters either relied on consortial publication or did not publish finding aids at all. These findings suggested that the majority of EAD adopters found the EAD delivery process difficult.

Table 5. Self and Consortial Publication

\begin{tabular}{|c|c|c|}
\hline & Number & Percentage \\
\hline Only self publication & 16 & $31.4 \%$ \\
Only consortial publication & 16 & $31.4 \%$ \\
Both & 6 & $11.7 \%$ \\
No publication & 13 & $25.5 \%$ \\
\hline Total & 51 & $100 \%$ \\
\hline
\end{tabular}

\section{Encoding vs. Publication}

The final set of findings on complexity compared the percentage of encoded and published finding aids. Out of $52 \mathrm{EAD}$ adopters, 33 encoded less than 10 percent of their finding aids. Out of those $33 \mathrm{EAD}$ adopters, 18 published less than 10 percent of their encoded findings. Therefore, the percentage of published finding aids was always less than that of encoded finding aids. This indicated that there was some delay between encoding and publishing EAD finding aids. Thus, the findings suggested that publishing EAD finding aids might be more difficult than encoding them.

\section{Discussion}

Through the results of this survey, three factors affecting the adoption of EAD were identified that require further discussion: 1) prior MARC adoption; 2) staff size; and 3) technical difficulties in encoding and delivery of finding aids. These have significance because they raise larger issues about the future diffusion of EAD in the archival community.

\section{Prior MARC Adoption}

The analysis showed that prior MARC adoption was positively related to EAD adoption. Since EAD was developed through incorporating MARC structures, skills and practices used in MARC were compatible of those of AD. Pitti (1997) mentioned three aspects that demonstrated this compatibility. First, MARC was a communitydeveloped standard. This shared buy-in created an atmosphere of cooperation. Furthermore, since the archival community had a common interest in creating a means for union access to collections, MARC capitalized on this value and enabled the establishment of large union databases for archival and manuscript materials. Second, MARC was based on descriptive encoding, which involved designating data structure, value, and content standards for various data fields. This descriptive markup supported flexible processing of information and much of this structure found its way into EAD. Third, MARC is a publicly-owned standard and therefore, it ensured that cataloging information would endure in the rapidly changing computer environment. Since EAD has the same three characteristics, MARC adopters could readily recognize and appreciate them. Thus, they were more likely to adopt EAD, as it was consistent with their existing practices and values.

MARC can also be considered as related technical knowledge. Previous innovation studies (Fichman and Kemerer 1997) have shown that prior acquisition of related expertise influences adoption of later innovations. Institutions using MARC already possessed related knowledge needed to implement EAD. Therefore, they adopted EAD more quickly and easily. If we were to identify one factor as a key predictor of EAD adoption, it would be prior utilization of the MARC format. This is significant because there are major portions of the archival community that have not adopted MARC.

\section{Size of Professional Staff}

A second factor that positively related to EAD adoption was staff size. This result raises a question regarding how small, archival institutions can adopt EAD. Early EAD implementers were concerned about this issue. Dow (1997) mentioned that comprehending and implementing EAD was difficult for small archival repositories because they were largely understaffed, under-funded and poorly trained. Two means of helping smaller repositories overcome the challenges of EAD implementation are the EAD Cookbook and consortia.

The EAD Cookbook was developed to provide a step-bystep guide for encoding, as well as using style sheets to transform EAD documents to HTML. Although the Cookbook was a useful tool, research has demonstrated that this does not greatly lower the barrier for smaller archives 
and special collections. Prom (2001), therefore, suggested three areas for extension: markup macros, digitization, and workflow design. We still do not know how effective these extensions are in lowering the bar. Since most of the archival institutions had limited resources, it will be difficult to achieve wider adoption of EAD without offering an effective way of EAD implementation for small-sized institutions.

Consortia are another mechanism developed to increase the participation of smaller repositories in EAD activities. However, even consortial participation requires resources. We found that the average professional staff size of EAD adopters was 4 and the average total staff size was 10 for both consortial and non-consortial participants. This is quite large for archival agencies. The last reliable statistics from the 1996 Society of American Archivists Salary Survey indicated that $58 \%$ of the respondents worked in archival units with 1-3 FTE professional archivists. This means that a majority of archives will never be able to sustain an EAD program by themselves and other models must be developed for EAD to be implemented in smaller repositories.

\section{Technical Difficulties in Encoding and Delivery}

Technical infrastructure was not found to be a major hindrance of EAD adoption. Tatem (1998) argued that much of the complexity of EAD was tied to the availability of software applications. She suggested that archivists experienced with several software products should provide software reviews for other archivists. Prom (2002) also argues for the development of software specifically tailored to EAD markup, which would allow for more consistent search and display mechanisms. Such software would need to be easy enough to implement without special training and advanced computer skills.

The low level of server control by all repositories may explain the lag between encoding and publication demonstrated in the findings. The lack of server control means that archives and special collections wanting to mount finding aids must have some access to server rights and rely on the technical expertise of the network administrators and the archivist's or curator's ability to assist the network administrator in designing and configuring an EAD portal. The fact that $25 \%$ of the EAD adopters have only encoded and not published is also a cause for concern. This cannot be explained solely by the lack of server control and indicate that a degree of trialability, one of Rogers factors not discussed here, is taking place.

\section{Conclusions}

Our findings demonstrated that EAD has not been widely adopted among participants in EAD workshops. Given that these workshop participants were perhaps more predisposed to adopting EAD, this does not bode well for EAD adoption in the wider archival community. However, further research is needed in this area.

This study does show, however, that EAD adoption is related to prior acceptance of standardized descriptive practices. Unfortunately, none have been universally accepted in the archival community. Furthermore, EAD will not succeed if mechanisms to facilitate the encoding and publication processes in smaller repositories are not more fully developed and financially supported on a wider scale. In the end, these mechanisms may benefit all archives and manuscript collections if they lessen the complexity of EAD, particularly the publication process.

EAD is in a critical period right now. It has the potential to become the standard for creating detailed union databases pointing to primary sources, creating the type of resource in the digital environment that archivists only dreamed of in the print environment. This would greatly benefit the edu-cational and scholarly research communities. If not, EAD may become a failed innovation and archivists will need to continue the quest for access tools that increase the availability of archival and manuscript materials.

\section{REFERENCES}

Dow, Elizabeth. 1997. EAD and the Small Repository. American Archivist, 60(3): pp. 446-455.

Duff, Wendy. 1999. The Acceptance and Implementation of the Rules for Archival Description by Canadian Archives: A Survey. Archivaria, 47: pp.27-45.

Fichman, R. G. \& C. Kemerer. 1997. The Assimilation of Process Software Innovations: An Organizational Learning Perspective. Management Science, 43(10): pp.1345-1363.

Fox, Michael J. 1997. Implementing Encoded Archival Description: an Overview of Administrative and Technical Considerations. American Archivist, 60(3): pp. 330-343.

Kiesling, Kris. 1997. EAD as an Archival Descriptive Standard. American Archivist, 60 (3): pp.344-354.

Marshall, Jennifer A. 2002. The Impact of EAD Adoption on Archival Programs: a Pilot Survey of Early Implementers. Journal of Archival Organization, 1(1): pp.35-55.

Martin, Lyn M. Viewing the Field: A Literature Review and Survey of the Use of U.S. MARC AMC in U.S. Academic Archives. American Archivist, 57: pp. 482-497.

Minks, Gina L.B. \& Lori Curtis. 2002. The University of Tulsa Digitization Initiative: A Blueprint for EAD implementation in the Small Academic Library. Retrieved December 22, 2003 from $\mathrm{http}: / /$ www.amigos.org/fellowship/2002_blueprint.pdf.

Morris, Leslie A. 1997. Developing a Cooperative IntraInstitutional Approach to EAD Implementation: the Harvard/Radcliffe Digital Finding Aids Project. American Archivist 60(4): 388-407.

Pitti, Daniel V. 1997. Encoded Archival Description: The development of an encoding standard for archival finding aids. American Archivist 60(3): pp.268-283. 
Prom, Christopher J. 2001. Extending the Capabilities of the EAD Cookbook. OCLC Systems and Services, 17(2): pp. 89-95.

Prom, Christopher J. 2002. The "EAD Cookbook": A Survey and Usability Study. American Archivist, 65(2): pp. 257-275.

Rogers, Everett M. 1995. Diffusion of Innovations. New York: Free Press.

Roth, James M. 2001. "Serving up EAD: an exploratory study on the deployment and utilization of Encoded Archival Description finding aids." American Archivist 64(2): 214-237.

Ruth, Janice E. 2001. "The Development and Structure of the Encoded Archival Description (EAD) Document Type
Definition." In: Encoded Archival Description on the Internet. pp. 27-60.

Society of American Archivists, 1996. 1996 Salary Survey, Chicago, IL: Society of American Archivists.

Tatem, Jill M. 1998. EAD: Obstacles to Implementation, Opportunities for Understanding Encoded Archival Description. Archival Issues, 23(2), pp. 155-169.

White, Marilyn Domas. 2001. Diffusion of an Innovation: Digital Reference Service in Carnegie Foundation Master's (Comprehensive) Academic Institution Libraries. The Journal of Academic Librarianship, 27(3): pp.173-187. 